\title{
The case for recording events in clinical trials
}

\author{
D C G SKEGG， RICHARD DOLL
}

British Medical fournal, 1977, 2, 1523-1524

\section{Summary}

The value of clinical trials in detecting unwanted effects of new medicines would be enhanced if doctors recorded all adverse events experienced by patients and not just those regarded as adverse reactions to drugs. All events should be reported to the centre co-ordinating the trial and analysed in treated patients and controls. This method might have revealed the ocular toxicity of practolol before the drug was marketed in 1970 .

\section{Weakness of clinical trial practice}

Understandably, some doctors are tired of hearing about practolol. We must, however, do everything possible to ensure that such a tragedy is not repeated. The practolol episode has been regarded as a failure of drug monitoring. Present awareness of the frequency of reactions (which were demonstrable in a study of 71 patients in general practice ${ }^{1}$ ) suggests that clinical trial technique as undertaken by even the most responsible and experienced clinicians was, and still is, insufficiently developed.

The trials that preceded release of practolol were as large and carefully conducted as for most new drugs. Manufacturers are required to report to the Committee on Safety of Medicines "all adverse reactions, whether major or minor.". The manufacturers of practolol went further: they reported their experi-

Department of the Regius Professor of Medicine, University of Oxford, Oxford OX2 6HE

D C G SKEGG, BMEDSC, MB, lecturer in epidemiology

RICHARD DOLL, FRCP, FRS, regius professor of medicine ence to the profession in a paper that was subsequently published. ${ }^{3}$ The paper analysed the unwanted effects encountered in 2100 patients, 900 of whom received oral treatment (223 for between six months and two years). Surprisingly, there were only seven rashes (of various types) and no eye complaints-an incidence far smaller than we would expect from subsequent experience. The explanation lies not in intentional concealment but in a weakness of clinical trial practice as generally accepted.

Consider the trial of a new hypotensive agent. Each patient is questioned about symptoms and his blood pressure is measured in various postures. A battery of clinical and laboratory tests is included to detect predictable toxicity. If, however, the patient complains of conjunctivitis he may be gently advised to consult his general practitioner. Such routine problems are usually reported to the trial co-ordinator only if a drug reaction is suspected. Adverse reactions often masquerade as coincidental disease and escape suspicion. ${ }^{4}$ Even if a drug reaction seems possible-and this is surely true of most rashes-it is extremely difficult to decide whether the drug is responsible, ${ }^{5}$ and when doctors are enthusiastic about a new treatment they may be reluctant to blame the drug.

\section{Need to report adverse events}

The weakness in current practice is that doctors usually report suspected adverse reactions, instead of all adverse events occurring in treated patients and controls. An adverse event is a "particular untoward happening experienced by a patient."6 It might be conjunctivitis, a rash, or a broken leg. Most adverse events would be unrelated to the treatment being studied. If, however, a particular event was more (or less) common among treated patients than controls suspicion would be aroused and the explanation sought. Recording of events would improve detection of adverse reactions, as well as estimation of their incidence.

Finney $^{6}$ emphasised the importance of this approach in 
monitoring drugs after marketing. An example of its usefulness was provided by the Boston Collaborative Drug Surveillance Program, which found that $26^{\circ}{ }_{0}$ of 105 patients given ethacrynic acid intravenously developed gastrointestinal bleeding, compared with $4.5 \%$ of other patients. ${ }^{7}$ None of the attending doctors attributed the bleeding to this drug. The limited experience of individual doctors and lack of prior suspicion prevented them from guessing the cause, but combining their observations led to discovery of an important reaction.

How can event-recording be accomplished in clinical trials? Doctors already ask patients about their symptoms. Use of checklists increases the number of symptoms elicited, but may interfere with detection of the important ones. ${ }^{8}$ Patient questionnaires may be useful. ${ }^{9}$ The only developments needed are methods for recording all adverse events and for transmitting them to the co-ordinating centre. There they must be coded and analysed. This will require extra effort and expense, but need not prolong the trial period.

Because they include a few thousand patients at most, clinical trials of new drugs can provide information about only common adverse effects. ${ }^{10}$ This has led to pessimism about the value of trials in detecting toxicity, and attention has been focused on the undeniable importance of post-marketing surveillance. There are, however, several reasons why we should make the most of the trials that are done. Firstly, the commonest reactions are often the most important. Secondly, minor complaints may be a clue to more serious (although less common) toxicity, as would have been the case with practolol. ${ }^{1}$ Thirdly, suspicions raised by clinical trials, even when firm conclusions are not possible, may lead to more effective monitoring after a drug is released. ${ }^{11}$

It has recently been suggested that all doctors using new drugs should report adverse events to the Committee on Safety of Medicines, but it is doubtful if compliance could be ensured without some provision for automatically recording the use of the drugs, as Inman has proposed. ${ }^{12}{ }^{13}$ Event-recording in clinical trials is even more urgent and would be easier to implement. Its introduction could make the initial clinical trials much more effective.

\section{References}

${ }^{1}$ Skegg, D C G, and Doll, R, Lancet, 1977, 2, 475.

2 Department of Health and Social Security, Notes on Applications for Clinical Trial Certificates. Unpublished, 1977.

${ }^{3}$ Wiseman, R A, Postgraduate Medical fournal, 1971, 47, suppl No 2, 68 .

${ }^{4}$ Vere, D W, Adverse Drug Reaction Bulletin, 1976, No 60.

${ }^{5}$ Karch, F E, et al, Clinical Pharmacology and Therapeutics, 1976, 19, 489.

${ }^{6}$ Finney, D J, Fournal of Chronic Diseases, 1965, 18, 77.

7 Jick, H, et al, fournal of the American Medical Association, 1970, 213, 1455.

${ }^{8}$ Huskisson, E C, and Wojtulewski, J A, British Medical fournal, 1974, 2, 698.

${ }^{9}$ Bulpitt, C J, and Dollery, C T, British Medical fournal, 1973, 3, 485.

10 Dollery, C T, Fournal of the Royal College of Physicians, 1977, 11, 226.

11 Anello, C, in Drug Monitoring, ed F Gross and W H W Inman. London, Academic Press, 1977.

12 British Medical fournal, 1977, 1, 861.

${ }^{13}$ Inman, W H W, in Drug Monitoring, ed F Gross and W H W Inman. London, Academic Press, 1977.

\title{
Breast carcinoma associated with pregnancy: a clinician's dilemma
}

\author{
G G RIBEIRO, M K PALMER
}

British Medical fournal, 1977, 2, 1524-1527

\section{Introduction}

Management of breast carcinoma associated with pregnancy may be a severe test for any clinician. Widely differing views are held by surgeons, gynaecologists, and radiotherapists about its treatment and prognosis. In addition, non-clinical religious, psychological, and socioeconomic considerations will influence the choice of management.

The rarity of breast carcinoma during pregnancy means that no one institution can accumulate a wide experience, even over a long period. Only two large personal series have been published. Holleb and Farrow ${ }^{1}$ reported on 283 patients from the Memorial Hospital for Cancer and Allied Diseases and Peters ${ }^{2}$ from the Ontario Cancer Institute reported on 126 patients in 1962, extending the series to 295 patients in $1968 .^{3}$ Based on her extensive studies, Peters expressed strong views on the management of breast carcinoma associated with pregnancy. Clinicians have probably been most influenced by her views, which are widely quoted, and we have therefore compared and contrasted our findings with those of Peters.

Christie Hospital and Holt Radium Institute, Manchester M20 9BX G G RIBEIRO, MB, FRCR, consultant radiotherapist

M K PALMER, BSC, FSS, senior medical statistician

\section{Patients, methods, and analysis}

Our series consisted of 128 patients with carcinoma of the breast who were pregnant. From 1941 to 1969 all these patients were referred to the Christie Hospital and Holt Radium Institute, Manchester, where they were divided into two groups.

Concurrent pregnancy group-Patients where the breast carcinoma was diagnosed during pregnancy or up to one year after childbirth.

Subsequent pregnancy group-Patients who became pregnant after completing treatment for primary breast carcinoma.

Eighty-eight patients were studied in the concurrent group and 40 patients in the subsequent pregnancy group. Three patients had two pregnancies each and therefore were included in both groups.

We have preferred to divide the phases of pregnancy into trimesters rather than into two halves as Peters has done, as we think that the former is more relevant to the practice of gynaecology and obstetrics in Britain.

Survival curves for various groups were calculated by the life-table method and compared by using the log-rank test ${ }^{4} ;$ this test was chosen because it compares the entire distributions of survival times rather than just the percentages of survivors at a fixed point in time-for example, five years.

Staging-All the patients had histological verification of carcinoma. The pathological node state was also known in all the operable patients and was taken into account when staging the disease. Staging was according to the International Clinical Staging."

Incidence-T $\mathrm{T}$ White ${ }^{6}$ reviewed 1375 cases of breast carcinoma associated with pregnancy reported from 1866 to 1953 and added 38 cases to extend the series to 1413 patients. ${ }^{7} \mathrm{He}$ calculated the frequency as three cases of breast carcinoma per 10000 pregnancies, or $2.8 \%$ of all breast carcinomas. Peters ${ }^{3}$ placed the figure slightly higher at $3.8 \%$ of all breast carcinomas. Almost 31000 cases of breast carcinoma 